\title{
Cesium Salt of Sodium 30-Tungstopentaphosphate: An Effective and Green Polyoxometalate for Synthesis of Gold Nanoparticles along with Decoration of Titanium Dioxide with Gold Nanoparticles for Bleaching of Malachite Green
}

\author{
Fatemeh Farrash Bamoharram, ${ }^{1}$ Afsaneh Moghadam Jafari, ${ }^{1}$ Ali Ayati, ${ }^{2}$ \\ Bahareh Tanhaei, ${ }^{2}$ and Mika Sillanpääa \\ ${ }^{1}$ Department of Chemistry, Mashhad Branch, Islamic Azad University, Mashhad 91735-413, Iran \\ ${ }^{2}$ Laboratory of Green Chemistry, Department of Chemistry, Lappeenranta University of Technology, \\ Sammonkatu 12, 50100 Mikkeli, Finland \\ Correspondence should be addressed to Fatemeh Farrash Bamoharram; fbamoharram@gmail.com
}

Received 1 October 2013; Revised 12 November 2013; Accepted 13 November 2013

Academic Editor: Vincenzo Augugliaro

Copyright (C) 2013 Fatemeh Farrash Bamoharram et al. This is an open access article distributed under the Creative Commons Attribution License, which permits unrestricted use, distribution, and reproduction in any medium, provided the original work is properly cited.

\begin{abstract}
For the first time, capability of the cesium salt of sodium 30-tungstopentaphosphate, the so-called Preyssler's anion $\left(\mathrm{CsP}_{5}\right)$, as a green and eco-friendly polyoxometalate was investigated in the synthesis of gold nanoparticles and decoration of titanium dioxide with gold nanoparticles. Gold nanoparticles and nanocomposites were characterized by TEM, XRD, UV, and FTIR. TEM images showed that the gold nanoparticles have tubular and spherical shapes and particle size ranges from 10 to $25 \mathrm{~nm}$. For gold-decorated titanium dioxide/Preyssler, a comparison between pure and amine-modified titanium dioxide showed higher loading of gold nanoparticles on amine-functionalized titanium dioxide. The performance of $\mathrm{CsP}_{5}$ was compared with its pure acid $\left(\mathrm{HP}_{5}\right)$. Our findings showed that $\mathrm{CsP}_{5}$, as a catalytic linker to bind onto titanium dioxide surface for reducing gold nanoparticles, renders decoration better than $\mathrm{HP}_{5}$ in both pure and modified titanium dioxide. In addition, efficiency of the photocatalytic bleaching of malachite green by the synthesized nanocomposites was found to be excellent.
\end{abstract}

\section{Introduction}

The recent advances in green catalysis, particularly when coupled with modifying of inorganic materials, have opened new avenues for the catalytic technology. One of the most important inorganic materials is titanium dioxide and different applications of it have been discovered in many fields, including photovoltaics $[1,2]$, photocatalysis $[3,4]$, selfcleaning coatings [5], and photoelectrocatalytic degradation of organic compounds $[6,7]$.

But, despite these large range of applications, the application of these particles is limited by the challenge of electronhole recombination and their band-gap energy of $3.2 \mathrm{eV}[8]$, which requires exposure to ultraviolet light for photocatalytic applications. For overcoming the electron-hole recombination phenomenon, many researchers have made an attempt to shift the band-gap energy of titanium dioxide toward the visible region [9-11] and used doping with small amounts of transition metals $[12,13]$.

To this end, titanium dioxide has been decorated with metals and metal oxides through chemical or photodeposition methods [14-23].

However, in deposition of metal nanoparticles on titanium dioxide surface, the final product contains a mixture of both metal nanoparticles and metal-decorated titanium dioxide. A possible solution to overcome this problem could be based on the immobilization of a reducing agent on the surface of titanium dioxide particles.

Polyoxometalates can reduce easily without any change in the structure and the reduced form of them bound to titanium dioxide can act as a reducing agent for metal ions to decorate metal nanoparticles, specifically on titanium 
dioxide surfaces [24]. Pearson and coworkers demonstrated decoration of titanium dioxide with metal nanoparticles using Keggin as an efficient polyoxometalate [25]. In addition, polyoxometalates can reduce noble metals to prepare nanoclusters in the presence of light $[26,27]$. Anyway, although there are many structural types of polyoxometalates, the majority of processes use the most common Keggin type, owing to its availability and chemical stability, and the role of Preyssler polyoxometalate, $\left[\mathrm{NaP}_{5} \mathrm{~W}_{30} \mathrm{O}_{110}\right]^{14-}$, has been largely overlooked.

The oval-shaped Preyssler polyoxometalate consists of a cyclic assembly of five $\mathrm{PW}_{6} \mathrm{O}_{22}$ units, each derived from the spherical Keggin anion, $\left[\mathrm{PW}_{12} \mathrm{O}_{40}\right]^{3-}$, by the removal of two sets of three corner-sharing $\mathrm{WO}_{6}$ octahedra. The $\left[\mathrm{XM}_{12} \mathrm{O}_{40}\right]^{n-}$ (Keggin structure) consists of one $\mathrm{XO}_{4}$ tetrahedron surrounded by four $\mathrm{M}_{3} \mathrm{O}_{13}$ sets linked together through oxygen atoms. The Preyssler's anion structure consists of five $\mathrm{PO}_{4}$ tetrahedron surrounded by $30 \mathrm{WO}_{6}$ which are connected to each other by edge and corner-sharing oxygens. A sodium ion is located within the polyanion on the five-fold axis and $1.25 \AA$ above the pseudomirror plane that contains the five phosphorus atoms.

The properties of polyoxometalates such as thermal stability as well as hydrolytic stability and catalytic activity are sensitive to their structures $[28,29]$. In addition, the kind and number of counterions as well as their constituent elements have an important effect on the catalytic activity, chemical behavior, and the redox properties of the polyoxometalates. Due to these reasons, a different behavior and activity is expected for each polyoxometalate with a different structure. Among a wide variety of studied heteropolyacids (an important class of polyoxometalates) with different size and structures, there are only three anions, $\left[\mathrm{NaSb}_{9} \mathrm{~W}_{21} \mathrm{O}_{86}\right]^{-}$, $\left[\mathrm{NaAs}_{4} \mathrm{~W}_{40} \mathrm{O}_{140}\right]^{25-}$, and $\left[\mathrm{NaP}_{5} \mathrm{~W}_{30} \mathrm{O}_{110}\right]^{14-}$ that have been reported to encapsulate rare-earth ions [30-32]. The latter of these, Preyssler's anion, is one of the largest known polyanions and important advantages of this polyanion over the Keggin and Dawson heteropolyacids are (i) more thermal stability, (ii) more hydrolytic stability $(\mathrm{pH}=0-$ 12), (iii) larger number of counter cations, and (iv) larger number of metal atoms. These properties are very important in catalytic processes, especially when we work in acidic and basic conditions. For example, while Keggin and Dawson, $\left[\mathrm{X}_{2} \mathrm{M}_{18} \mathrm{O}_{62}\right]^{n-}$, polyoxometalates are stable in $\mathrm{pH}=1-3$ and 16 , respectively, the Preyssler is stable in $\mathrm{pH}=0-12$. Additionally, while the oxidation of organic substrates by hydrogen peroxide in the presence of Keggin proceeds via degradation of structure to an active peroxopolyoxometalate, the Preyssler catalyst catalyzes the reactions without any degradation of structure [33]. This is very important in catalytic reactions in the presence of hydrogen peroxide. The large anion with the larger number of metal atoms also provides many "sites" on the oval-shaped molecule that are likely to render the catalyst effective, better than Keggin and Dawson types.

In continuation of our works on applications of Preyssler acid, $\mathrm{H}_{14}\left[\mathrm{NaP}_{5} \mathrm{~W}_{30} \mathrm{O}_{110}\right]$, in catalytic and photocatalytic reactions $[34,35]$ and cited references in [35] and extending the applications of Preyssler, and also due to the importance of metal-titanium dioxide decoration, it is highly relevant to know what occurs if the Preyssler's anion joins with titanium dioxide and use it as a catalytic linker for reducing gold ions. In addition, it is also important to investigate the role of another polyoxometalates apart from Keggin heteropolyacids. We think the most important and credential part of our work is to introduce and establish nanocesuim salt of Preyssler type heteropolyacid, $\mathrm{Cs}_{12} \mathrm{H}_{2}\left[\mathrm{NaP}_{5} \mathrm{~W}_{30} \mathrm{O}_{110}\right]$, which can be applied as an efficient and competing nanocatalyst with those of Keggin type which have been already reported as bulk.

Also, another goal in this research was to answer this question: does counter cation in the Preyssler structure, which is responsible for primary, secondary, and tertiary structures, have an important role on loading of gold nanoparticles onto titanium dioxide?

To this purpose, in the present work, at first in continuation of our earlier works [36], we investigated the performance and capability of cesium salt of sodium 30tungstopentaphosphate, $\mathrm{Cs}_{12} \mathrm{H}_{2}\left[\mathrm{NaP}_{5} \mathrm{~W}_{30} \mathrm{O}_{110}\right]$, in synthesis of gold nanoparticles and after that, we studied decoration of titanium dioxide with gold nanoparticles in the presence of the Preyssler with different counterions including $\mathrm{Cs}^{+}$and $\mathrm{H}^{+}$. Interestingly, we have found that the Preyssler catalyst with $\mathrm{Cs}^{+}$as counterion not only can change shape and size of gold nanoparticles but also can lead to a higher loading of gold nanoparticles onto titanium dioxide. Also we have investigated the application of different forms of Preyssler nanocomposites for bleaching of malachite green.

\section{Experimental}

2.1. Materials and Methods. All of the chemicals were purchased from Merck and Sigma Aldrich Companies and used as received. FT-IR spectra were recorded with a Brucker scientific spectrometer (solid sample, $\mathrm{KBr}$ pellets). The synthesized nanostructures were characterized by Transmission Electron Microscopy (PHILIPS CM-120 and JEOL-2200FS FEG). A double beam spectrophotometer UV-Vis was used for UV-Vis analysis (OPTIZEN 3220).

2.2. Preparation of $\mathrm{HP}_{5}$ and $\mathrm{Cs} \mathrm{P}_{5}$. At first, $33 \mathrm{~g} \mathrm{Na}_{2} \mathrm{WO}_{4}$. $2 \mathrm{H}_{2} \mathrm{O}$ was dissolved in $45 \mathrm{~mL}$ water by stirring; and then $25 \mathrm{~mL}$ of phosphoric acid $85 \%$ was added. The mixture was refluxed for $5 \mathrm{~h}$. After that, $10 \mathrm{~mL} \mathrm{H}_{2} \mathrm{O}$ and $10 \mathrm{~g} \mathrm{KCl}$ were added into the above mixture to form a light green precipitate. The green precipitate was obtained by filtration and washed successively by $2 \mathrm{M}$ aqueous solution of $\mathrm{CH}_{3} \mathrm{COOK}$ and methanol. Recrystallization in hot water led to formation of $\mathrm{K}_{12.5} \mathrm{Na}_{1.5}\left[\mathrm{NaP}_{5} \mathrm{~W}_{30} \mathrm{O}_{110}\right]$ in needle white color crystals.

Preyssler acid, $\mathrm{H}_{14}\left[\mathrm{NaP}_{5} \mathrm{~W}_{30} \mathrm{O}_{110}\right]\left(\mathrm{HP}_{5}\right)$, was prepared by the passage of a solution of the $\mathrm{K}_{12.5} \mathrm{Na}_{1.5}\left[\mathrm{NaP}_{5} \mathrm{~W}_{30} \mathrm{O}_{110}\right]$ in water through a column $(50 \mathrm{~cm})$ of Dowex 50WX8 in the $\mathrm{H}^{+}$form and evaporation of the elute to dryness under vacuum.

For the preparation of $\mathrm{CsP}_{5}$, Preyssler acid and $\mathrm{CsCl}$ in a mole ratio of $1: 14$ were put into a mortar and several drops of surfactant Triton X-100 were added. The formed microcells in the solid state reaction owing to the interaction between 
the crystal water of Preyssler and the triton-X-100 are metastable and provide reaction fields for the formation of nanoparticles. The mixture was ground for $50 \mathrm{~min}$ and after washing in an ultrasonic bath, the mixture was centrifuged. The synthesized nanoparticles dried in an oven for $4 \mathrm{~h}$ (50$60^{\circ} \mathrm{C}$ ). The number of obtained Cs ions was 12 , measured by ICP measurement and titration method. Preyssler acid is highly soluble in water but has lower surface area $\left(0.78 \mathrm{~m}^{2} / \mathrm{gr}\right)$ than acidic cesium salt of Preyssler $\left(2.61 \mathrm{~m}^{2} / \mathrm{g}\right)$.

2.3. Preparation of Titanium Dioxide-Cs $P_{5}$ and Amine-Functionalized Titanium Dioxide-CsP $P_{5}$. The functionalized titanium dioxide is prepared as follows.

$2.5 \mathrm{~g}$ of $\mathrm{TiO}_{2}$ was suspended in $25 \mathrm{~mL}$ toluene and refluxed for $1 \mathrm{~h}$; and then $1.25 \mathrm{~g} 3$-aminopropyltriethoxy silane was added into the above mixture with further stirring for $24 \mathrm{~h}$. The product was obtained by filtration, washed successively with toluene, ethanol, and water, and finally dried in vacuum at $80^{\circ} \mathrm{C}$ for $12 \mathrm{~h}$.

Titanium dioxide- $\mathrm{CsP}_{5}$ and amine-functionalized titanium dioxide- $\mathrm{CsP}_{5}$ were synthesized by impregnating titanium dioxide (anatase, Aldrich, 232033) and functionalized titanium dioxide powders with an aqueous solution of the $\mathrm{HP}_{5}$ or $\mathrm{CsP}_{5}$. After stirring the mixture, the solvent was evaporated to dryness. The obtained powders were dried in an oven at $80^{\circ} \mathrm{C}$.

2.4. Decoration with Gold Nanoparticles. In two parallel experiments, a suspension of the obtained powders, titanium dioxide- $\mathrm{CsP}_{5}$ and amine-functionalized titanium dioxide$\mathrm{CsP}_{5},(10 \mathrm{mg})$ was dispersed in an ultrasonic bath. After that, $5 \mathrm{~mL} \mathrm{HAuCl}_{4}\left(10^{-3} \mathrm{M}\right)$ and $2 \mathrm{~mL}$ propan-2-ol were added to each solutions; and then it was irradiated under the high pressure of mercury lamp as UV light source. After $1 \mathrm{~h}$, the suspensions were filtered, rinsed with water, and dried in a vacuum oven. The obtained nanocomposites were used in photocatalytic reactions.

2.5. Typical Procedure for Bleaching of Malachite Green. In a typical reaction, $0.01 \mathrm{~g}$ photocatalyst was added to $100 \mathrm{~mL}$ of malachite green $(10 \mathrm{ppm})$, sonicated for $10 \mathrm{~min}$, and left for $15 \mathrm{~min}$ in a dark place. The mixture was irradiated in a photoreactor. The photoreactor was designed with an internal light source surrounded by a quartz jacket. The temperature of the suspension was maintained at $25^{\circ} \mathrm{C}$ by circulation of water through an external cooling coil. The optical path length was about $2 \mathrm{~cm}$. The light source was a $125 \mathrm{~W}$ highpressure mercury lamp. The suspension was illuminated from the top and at given irradiation time intervals, liquid samples were taken from the mixture and the absorbance of the malachite green solution was measured with a UV-Vis spectrophotometer.

\section{Results and Discussion}

Synthesis of gold nanoparticles was performed with a onepot synthesis technique in the presence of Preyssler with $\mathrm{Cs}^{+}$as counterion. The used method is simple and efficient and takes place within a short time (15 min) at ambient temperature. Using Preyssler as a reducing agent and stabilizer, the synthesis of gold nanoparticles by photolysis of gold (III)/Preyssler/propan-2-ol solution was carried out.

Preyssler polyoxometalate (POM) plays the role of transferring electrons from propan-2-ol (S) to gold (III) and also stabilizing the nanoparticles (1). Consider

$$
\begin{gathered}
\mathrm{POM}+\mathrm{S} \longrightarrow \operatorname{POM}\left(\mathrm{e}^{-}\right)+\mathrm{S}_{\mathrm{OX}} \\
\operatorname{POM}\left(\mathrm{e}^{-}\right)+\mathrm{Au}^{3+} \longrightarrow \mathrm{POM}+\mathrm{Au}^{0}
\end{gathered}
$$

The morphology and size of gold nanoparticles were characterized by TEM. The TEM image is shown in Figure 1(b).

Interestingly, as we can see, counterions can affect both the size and the shape of the nanoparticles. So, when $\mathrm{H}^{+}$is a counterion, the shapes of the gold nanoparticles were nearly uniform hexagonal structures and the size of the synthesized gold nanoparticles varied from 13 to $43 \mathrm{~nm}$ (Figure 1(a)). When $\mathrm{H}^{+}$was replaced by $\mathrm{Cs}^{+}$, interestingly, a mixture of tubular and spherical gold nanoparticles with the size of 10$25 \mathrm{~nm}$ was obtained (Figure 1(b)). With respect to the fact that Preyssler with $\mathrm{Cs}^{+}$could change morphology and size of gold nanoparticles, it is suggested that the tertiary structure type has an important effect in this catalysis process.

There are three classes of structures which we call the primary, secondary, and tertiary structures [29]. Heteropolyanions in the solid state are ionic crystals consisting of large polyanions (primary structure), cations, water of crystallization, and other molecules. This three-dimensional arrangement is the secondary structure. In addition to these two structures, the tertiary structure is very influential on the catalytic function of solid heteropolyanions. Counter cations greatly influence the tertiary structure of heteropolyanions, and the salts are classified by the size of cation into group A (small metal cations like $\mathrm{Na}$ and $\mathrm{Cu}$ ) and group B (large metal cations like $\mathrm{Cs}, \mathrm{NH}_{4}$, etc.) [29]. So, we can conclude that the synthesis process can be controlled by tertiary structure of Preyssler. Also, from Figure 1, it is clear that there is no agglomeration. Usually there is a tendency of agglomeration via Coulomb or van der Waals forces in the synthesis process of nanoparticles [37]. Preyssler is an excellent stabilizer to prevent agglomeration. In addition, Preyssler is easily separated after the reaction and will not contaminate the gold nanoparticles.

Figure 2 shows UV-Vis absorption spectra of the synthesized gold nanoparticles. A surface plasmon resonance band of gold nanoparticles at about $530 \mathrm{~nm}$ appeared after 45 and $15 \mathrm{~min}$, in the presence of $\mathrm{HP}_{5}$ and $\mathrm{CsP}_{5}$, respectively. $\mathrm{UV}-\mathrm{Vis}$ analysis showed that in the presence of $\mathrm{CsP}_{5}$, gold nanoparticles were synthesized in shorter time.

TEM micrographs of gold-decorated titanium dioxidePreyssler with $\mathrm{H}^{+}$and $\mathrm{Cs}^{+}$as counterions are shown in Figure 3.

In comparison with $\mathrm{HP}_{5}$, there is a higher loading of gold nanoparticles on titanium dioxide in the presence of $\mathrm{CsP}_{5}$. Group B salts of polyoxometalates with larger metal ions like $\mathrm{Cs}^{+}$have higher surface area than group A. Thus, it is suggested that, because Preyssler acts as a localized reducing agent, a higher surface coverage with $\mathrm{CsP}_{5}$ results 


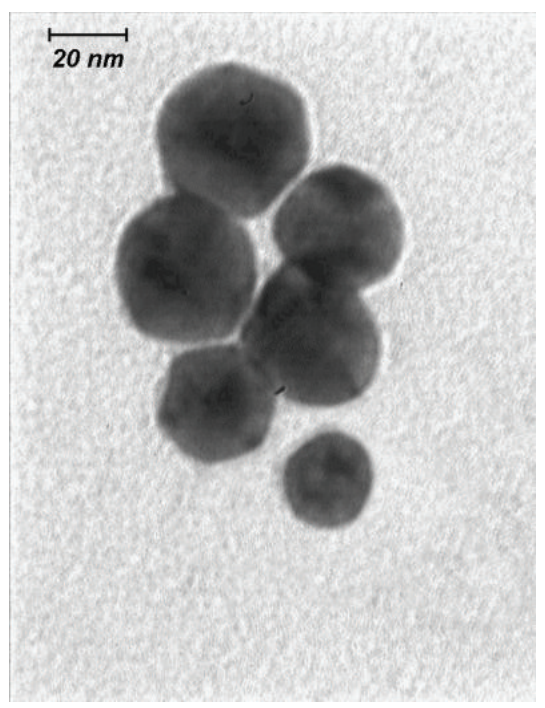

(a)

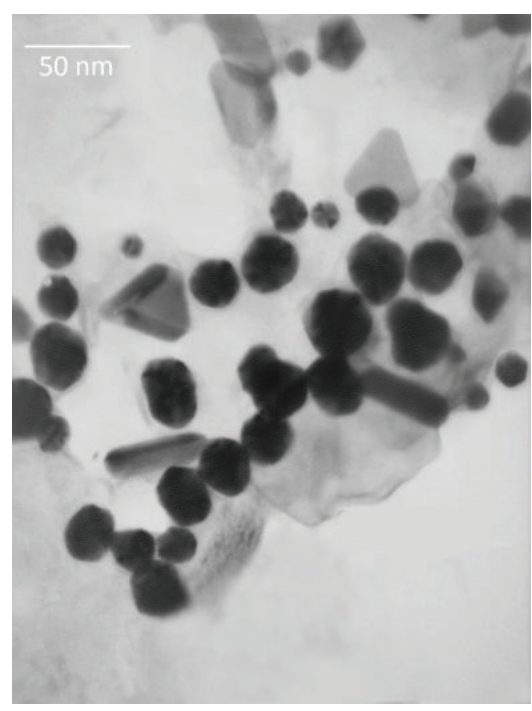

(b)

FIGURE 1: TEM images of the synthesized Au nanoparticles in the presence of $\mathrm{HP}_{5}^{36}(\mathrm{a})$ and $\mathrm{CsP}_{5}(\mathrm{~b})$.

in enhanced reduction of $\mathrm{HAuCl}_{4}$ to gold nanoparticles on titanium dioxide surface. The gold nanoparticles formed using $\mathrm{HP}_{5}$ and $\mathrm{CsP}_{5}$ are 2-10 and 20-50 nm, respectively.

TEM micrographs for decoration of the amine-functionalized titanium dioxide with gold nanoparticles are shown in Figure 4 . This figure shows higher loading of gold nanoparticles on amine-functionalized titanium dioxide. This higher loading can be related to strong electrostatic interactions between negatively charged Preyssler polyoxometalate with positively charged amine-functionalized titanium dioxide. Interestingly, for amine-modified titanium dioxide, higher loadings were obtained in the presence of $\mathrm{CsP}_{5}$ again. So, we can conclude that the tertiary structure in polyoxometalate, which led to a higher surface coverage, can control loading amounts.

Binding of Preyssler to titanium dioxide was confirmed by infrared spectroscopy as shown in Figure 5. Because

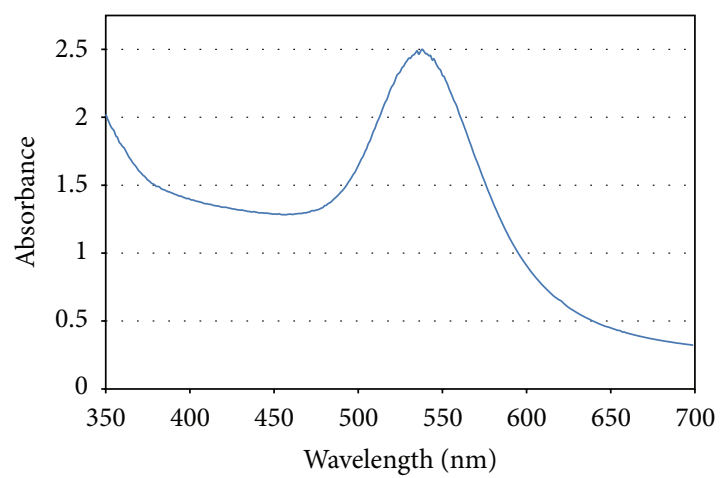

(a)

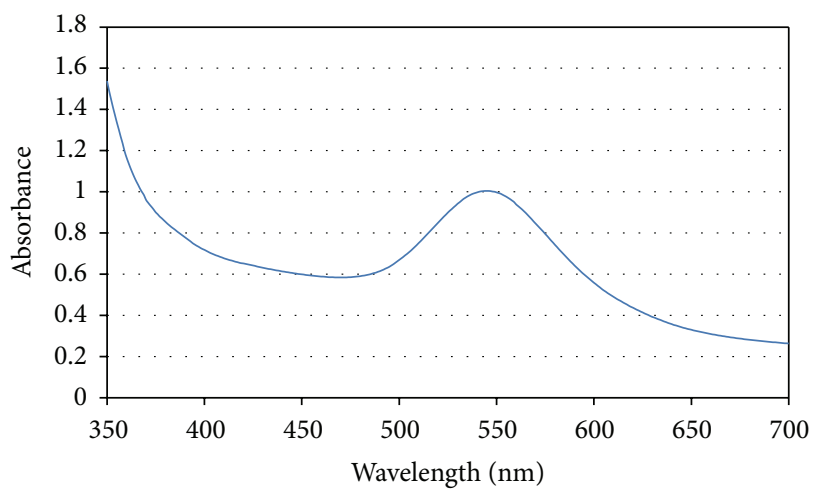

(b)

FIGURE 2: UV-Vis spectra of the synthesized gold nanoparticles in the presence of $\mathrm{HP}_{5}$ (a) and $\mathrm{CsP}_{5}$ (b).

intermolecular interactions lead to a change in the frequencies of the metal-oxygen stretching bands, as well as the intensity and position of the corresponding IR bands, FTIR spectroscopy can be used to confirm the interaction of HPAs with different molecules [38].

Preyssler's structure gives rise to four types of oxygen that are responsible for the fingerprints bands of Preyssler anion between 1200 and $600 \mathrm{~cm}^{-1}$. The characteristic bands of Preyssler structure, $\left[\mathrm{NaP}_{5} \mathrm{~W}_{30} \mathrm{O}_{110}\right]^{14-}$, are three bands due to $\mathrm{P}-\mathrm{O}$ stretching at $1163 \mathrm{~cm}^{-1}$ (medium), $1079 \mathrm{~cm}^{-1}$ (medium), and $1022 \mathrm{~cm}^{-1}$ (weak), and two bands attributed to $\mathrm{W}-\mathrm{O}-\mathrm{W}$ at $941 \mathrm{~cm}^{-1}$ (medium) and $913 \mathrm{~cm}^{-1}$ (weak), a band at $757 \mathrm{~cm}^{-1}$ (strong) corresponding to $\mathrm{W}=\mathrm{O}$ and a band at $536 \mathrm{~cm}^{-1}$ (strong) due to P-O bending. These bands can shift, weaken, strengthen, or mask in different conditions.

In Figure 5, compared with the initial Preyssler's structure, the bands arising from the synthesized nanocomposite changed obviously either in intensity or in position. Our findings show that many of the vibrational bands of Preyssler have blue-shifted and many of them have red-shifted, indicating that many of the bonds were strengthened and the others were weakened. As we can see, there is a significant shift in the W-O-W vibrations from 941 to $958 \mathrm{~cm}^{-1}$ and some displacements in the P-O stretchings from 1163 and $1079 \mathrm{~cm}^{-1}$ to 1156 and $1089 \mathrm{~cm}^{-1}$, respectively. The characteristic band in $913 \mathrm{~cm}^{-1}$ is unchanged and the $\mathrm{W}=\mathrm{O}$ band along with 


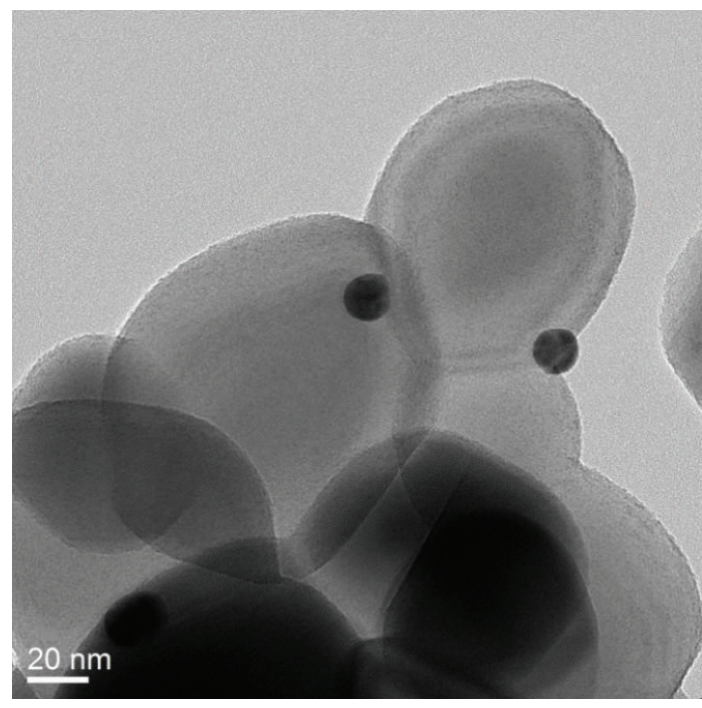

(a)

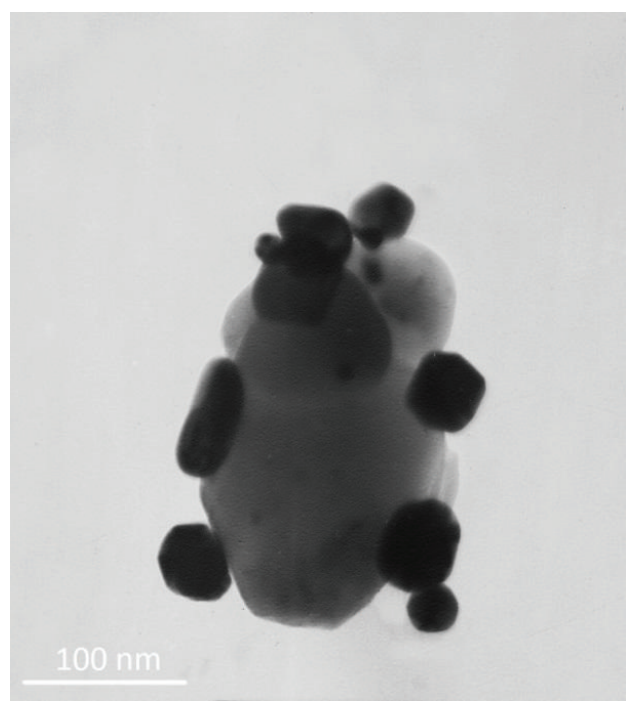

(b)

Figure 3: TEM images of $\mathrm{Au} / \mathrm{HP}_{5} / \mathrm{TiO}_{2}$ (a) and $\mathrm{Au} / \mathrm{CsP}_{5} / \mathrm{TiO}_{2}$ (b).

the P-O bending bands are overlapped by that of titanium dioxide. With respect to the $\mathrm{PO}_{4}$ tetrahedrons vibrating almost independently from the rest of the anion, the significant blue shift of $17 \mathrm{~cm}^{-1}$ in the $\mathrm{W}-\mathrm{O}-\mathrm{W}$ vibrational mode suggests that Preyssler interacts strongly with the titanium dioxide surface and binds to it by the oxygen atoms in the W-O-W positions.

Titanium dioxide does not have significant bands between 800 and $1200 \mathrm{~cm}^{-1}$ and shows a broad band between 600 and $800 \mathrm{~cm}^{-1}$. The $\mathrm{W}=\mathrm{O}$ band placed in the $757 \mathrm{~cm}^{-1}$ is masked by that of titanium dioxide. These observations indicate that the Preyssler's anion chemically adsorbed onto the surface of titanium dioxide and interaction between Preyssler's anions and support mostly caused the distortion of anion and thus substantially not only weakened the IR vibrations covered up by the titanium dioxide background, but also caused some displacements in some bands. It is

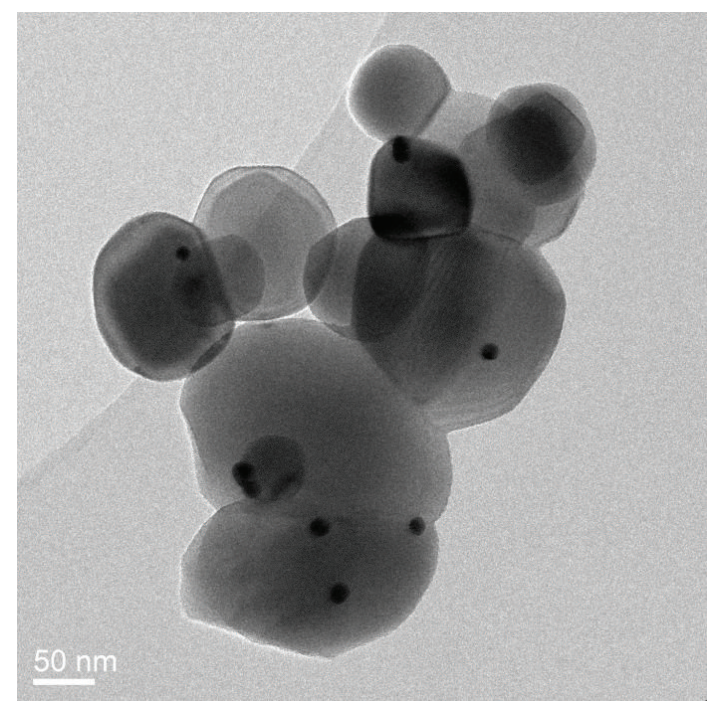

(a)

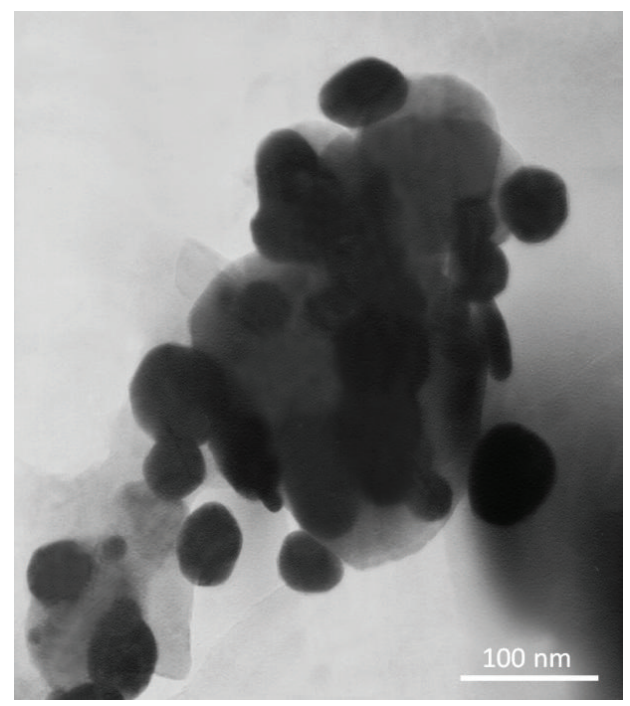

(b)

Figure 4: TEM images of $\mathrm{Au} / \mathrm{HP}_{5} / \mathrm{NH}_{2}-\mathrm{TiO}_{2}$ (a) and $\mathrm{Au} / \mathrm{Cs} \mathrm{P}_{5} /$ $\mathrm{NH}_{2}-\mathrm{TiO}_{2}(\mathrm{~b})$.

completely common in IR spectra of polyoxometalates, when interacting with different counter ions [39]. Additionally, the organosilanes and amine groups characteristic peaks $\left(2921,1637,1508\right.$, and $\left.1458 \mathrm{~cm}^{-1}\right)$ in the FTIR spectra of the nanocomposites confirmed the presence of ligand on the surface.

Finally, XRD analysis confirmed the presence of gold nanoparticles and titanium dioxide in the synthesized nanocomposites (Figure 6).

The bleaching of the malachite green in a designed photoreactor was performed as a test reaction to estimate the catalytic activity of both synthesized nanocomposites $\left(\mathrm{Au} / \mathrm{CsP}_{5} /\right.$ $-\mathrm{TiO}_{2}$ and $\mathrm{Au} / \mathrm{CsP}_{5} / \mathrm{NH}_{2}-\mathrm{TiO}_{2}$ ). We checked the intensity changes of UV band in malachite green in a photocatalytic reaction. Figure 7 summarizes UV-Vis results. It is clear that the photocatalytic activity strongly depends on the used catalyst. 


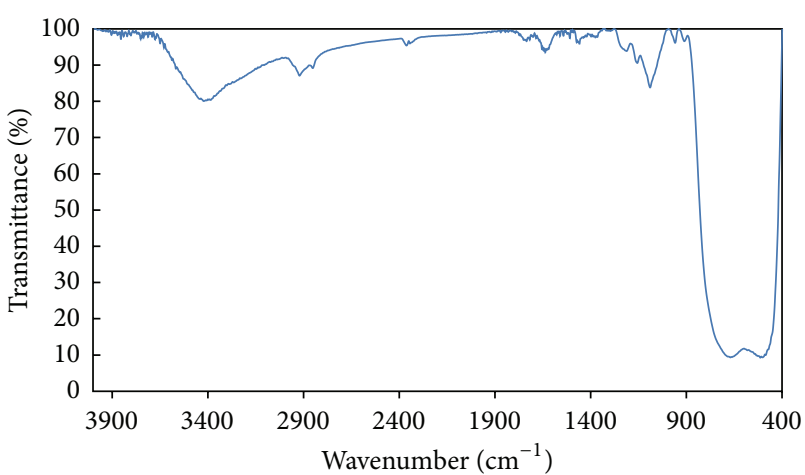

Figure 5: FTIR spectra of $\mathrm{Au} / \mathrm{Cs}-\mathrm{P}_{5} / \mathrm{NH}_{2}-\mathrm{TiO}_{2}$.

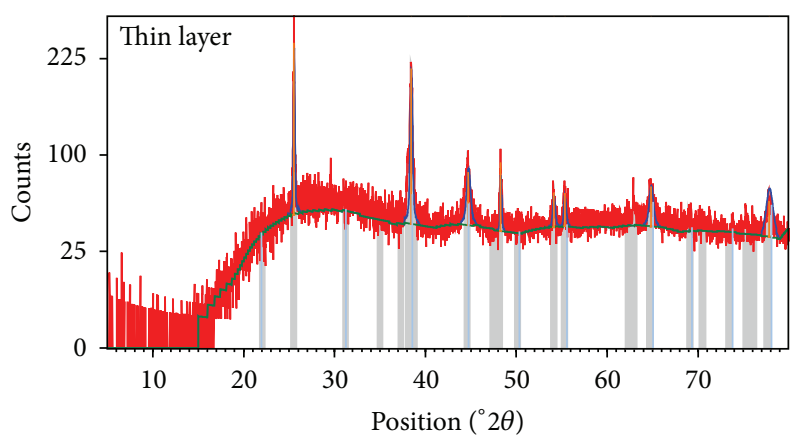

FIgURE 6: XRD pattern of $\mathrm{Au} / \mathrm{CsP}_{5} / \mathrm{TiO}_{2}$.

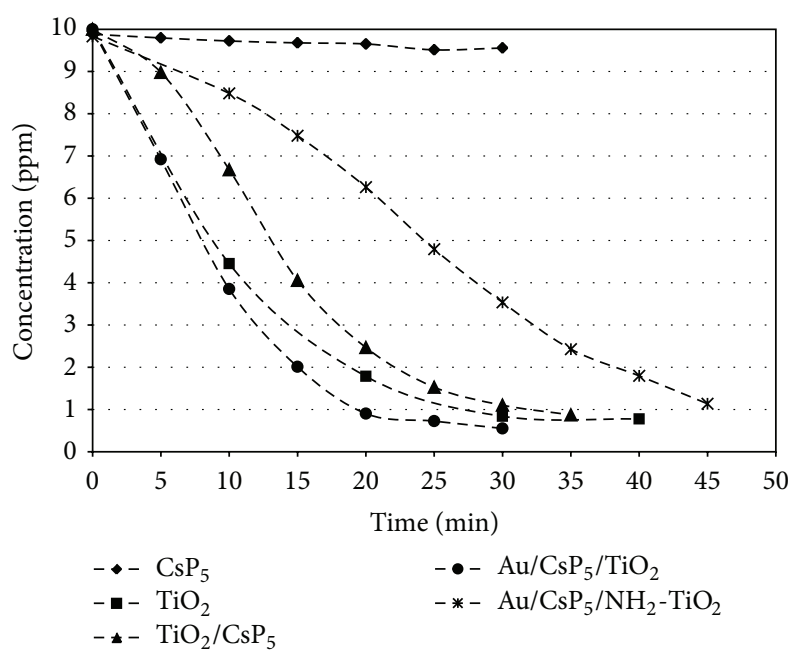

Figure 7: Bleaching of malachite green in the presence of $\mathrm{CsP}_{5}$, $\mathrm{TiO}_{2}, \mathrm{TiO}_{2} / \mathrm{CsP}_{5}, \mathrm{Au} / \mathrm{CsP}_{5} / \mathrm{TiO}_{2}$, and $\mathrm{Au} / \mathrm{CsP}_{5} / \mathrm{NH}_{2}-\mathrm{TiO}_{2}$.

As a control experiment series, in the same conditions we studied the bleaching of the dye in the presence of titanium dioxide, $\mathrm{CsP}_{5}$, and titanium dioxide- $\mathrm{CsP}_{5}$ (Figure 7). As we can see, there is an increase in photocatalytic activity, resulting in $100 \%$ bleaching of the dye after 20 minutes in the presence of $\mathrm{Au} / \mathrm{CsP}_{5} / \mathrm{TiO}_{2}$. As expected, when Preyssler joins with titanium dioxide, photocatalytic activity is increased. It is suggested that $\mathrm{CsP}_{5}$ as a cocatalyst can improve photocatalytic activity of titanium dioxide. The reduced photoactivity of $\mathrm{CsP}_{5}$-amine modified titanium dioxide-gold nanoparticles in Figure 7 can be attributed to higher gold loading in this nanocomposite, which might decrease the total effective titanium dioxide surface area during the bleaching of the dye. At the end of the reaction, the photocatalyst was filtered, washed, dried, and reused in another reaction. The recycled photocatalyst was used for three reactions without observation of appreciable loss in its catalytic activity. It is suggested that, because $\mathrm{CsP}_{5}$ is not very soluble, it is present in the photocatalysts during the dye bleaching runs.

\section{Conclusion}

Green, eco-friendly, recyclable, and easily preparable cesium salt of Preyssler's anion is an efficient solid acid catalyst for the synthesis of gold nanoparticles as well as decoration of gold nanoparticles on the surface of titanium dioxide. Important features of this polyanion are high thermal and hydrolytic stability throughout a wide $\mathrm{pH}$ range. Thus, a wide range of chemical reactions can be affected without loss of structure or activity. Our findings show that counterions play an important role in the decoration of titanium dioxide, and Preyssler acts as a reducing agent and catalytic linker.

We observed that both of the synthesized nanocomposites with pure and modified titanium dioxide exhibit excellent photocatalytic activity in the bleaching of malachite green when exposed to UV irradiation. The remarkable bleaching of malachite green in the presence of these nanocomposites indicates that the treatments of other organic pollutants could be performed in the presence of this catalyst in order to obtain a perfect bleaching degree. This catalytic activity can also be extended to the other photocatalytic reactions.

\section{References}

[1] H. Yu, S. Zhang, H. Zhao, B. Xue, P. Liu, and G. Will, "High-performance $\mathrm{TiO}_{2}$ photoanode with an efficient electron transport network for dye-sensitized solar cells," Journal of Physical Chemistry C, vol. 113, no. 36, pp. 16277-16282, 2009.

[2] H. Yu, S. Zhang, H. Zhao, and H. Zhang, "Photoelectrochemical quantification of electron transport resistance of $\mathrm{TiO}_{2}$ photoanodes for dye-sensitized solar cells," Physical Chemistry Chemical Physics, vol. 12, no. 25, pp. 6625-6631, 2010.

[3] M. R. Hoffmann, S. T. Martin, W. Choi, and D. W. Bahnemann, "Environmental applications of semiconductor photocatalysis," Chemical Reviews, vol. 95, no. 1, pp. 69-96, 1995.

[4] A. Fujishima, K. Hashimoto, T. Iyoda, S. Fukayama, T. Yoshimoto, and T. Saitoh, US Patent US6939611, 2005.

[5] G. K. Mor, O. K. Varghese, M. Paulose, and C. A. Grimes, "A self-cleaning room temperature titania-nanotube hydrogen gas sensor," Sensor Letters, vol. 1, no. 1, pp. 42-46, 2003.

[6] E. Bessa, J. G. L. SantAnna, and M. J. Dezotti, "Photocatalysis: an approach to the treatment of oil field produced waters," Journal of Advanced Oxidation Technologies, vol. 4, no. 2, pp. 196-202, 1999.

[7] J. C. Cardoso, T. M. Lizier, and M. V. B. Zanoni, "Highly ordered $\mathrm{TiO}_{2}$ nanotube arrays and photoelectrocatalytic oxidation of aromatic amine," Applied Catalysis B, vol. 99, no. 1-2, pp. 96-102, 2010. 
[8] A. Hagfeldt and M. Gratzel, "Molecular photovoltaics," Accounts of Chemical Research, vol. 33, no. 5, pp. 269-277, 2000.

[9] M. Anpo, "Photocatalysis on titanium oxide catalysts: approaches in achieving highly efficient reactions and realizing the use of visible light," Catalysis Surveys from Japan, vol. 1, no. 2, pp. 169-179, 1997.

[10] D. R. Baker and P. V. Kamat, "Photosensitization of $\mathrm{TiO}_{2}$ nanostructures with $\mathrm{CdS}$ quantum dots: particulate versus tubular support architectures," Advanced Functional Materials, vol. 19, no. 5, pp. 805-811, 2009.

[11] H. Kikuchi, M. Kitano, M. Takeuchi, M. Matsuoka, M. Anpo, and P. V. Kamat, "Extending the photoresponse of $\mathrm{TiO}_{2}$ to the visible light region: photoelectrochemical behavior of $\mathrm{TiO}_{2}$ thin films prepared by the radio frequency magnetron sputtering deposition method," Journal of Physical Chemistry B, vol. 110, no. 11, pp. 5537-5541, 2006.

[12] K. Wilke and H. D. Breuer, "The influence of transition metal doping on the physical and photocatalytic properties of titania," Journal of Photochemistry and Photobiology A, vol. 121, no. 1, pp. 49-53, 1998.

[13] P. Bouras, E. Stathatos, and P. Lianos, "Pure versus metalion-doped nanocrystalline titania for photocatalysis," Applied Catalysis B, vol. 73, no. 1-2, pp. 51-59, 2007.

[14] C. E. Gomez, J. R. V. Garcia, J. A. T. Antonio, M. A. C. Jacome, and C. A. J. Chavez, "Pt nanoparticles on titania nanotubes prepared by vapor-phase impregnation-decomposition method," Journal of Alloys and Compounds, vol. 495, no. 2, pp. 458-461, 2010.

[15] K. Nishijima, T. Fukahori, N. Murakami, T.-A. Kamai, T. Tsubota, and T. Ohno, "Development of a titania nanotube (TNT) loaded site-selectively with Pt nanoparticles and their photocatalytic activities," Applied Catalysis A, vol. 337, no. 1, pp. 105-109, 2008.

[16] Y. Yin, X. Tan, F. Hou, and L. Zhao, "Efficient synthesis of titania nanotubes and enhanced photoresponse of Pt decorated $\mathrm{TiO}_{2}$ for water splitting," Frontiers of Chemical Engineering in China, vol. 3, no. 3, pp. 298-304, 2009.

[17] B.-L. He, B. Dong, and H.-L. Li, "Preparation and electrochemical properties of Ag-modified $\mathrm{TiO}_{2}$ nanotube anode material for lithium-ion battery," Electrochemistry Communications, vol. 9, no. 3, pp. 425-430, 2007.

[18] I. Paramasivam, J. M. Macak, and P. Schmuki, "Photocatalytic activity of $\mathrm{TiO}_{2}$ nanotube layers loaded with $\mathrm{Ag}$ and $\mathrm{Au}$ nanoparticles," Electrochemistry Communications, vol. 10, no. 1, pp. 71-75, 2008.

[19] L. P. An, X. P. Gao, G. R. Li, T. Y. Yan, H. Y. Zhu, and P. W. Shen, "Electrochemical lithium storage of titania nanotubes modified with $\mathrm{NiO}$ nanoparticles," Electrochimica Acta, vol. 53, no. 13, pp. 4573-4579, 2008.

[20] A. Kukovecz, M. Hodos, Z. Konya, and I. Kiricsi, "Complexassisted one-step synthesis of ion-exchangeable titanate nanotubes decorated with CdS nanoparticles," Chemical Physics Letters, vol. 411, no. 4-6, pp. 445-449, 2005.

[21] A. Benoit, I. Paramasivam, Y.-C. Nah, P. Roy, and P. Schmuki, "Decoration of $\mathrm{TiO}_{2}$ nanotube layers with $\mathrm{WO}_{3}$ nanocrystals for high-electrochromic activity," Electrochemistry Communications, vol. 11, no. 4, pp. 728-732, 2009.

[22] M. A. Khan and O.-B. Yang, "Photocatalytic water splitting for hydrogen production under visible light on Ir and Co ionized titania nanotube," Catalysis Today, vol. 146, no. 1-2, pp. 177-182, 2009.
[23] M. Muruganandham, A. Ramakrishnan, Y. Kusumoto, and M. Sillanpää, "Are dopant-stabilized visible light-responsive photocatalysts efficient and stable?" Physical Chemistry Physical Chemistry, vol. 12, no. 44, pp. 14677-14681, 2010.

[24] A. Pearson, H. Jani, K. Kalantarzadeh, S. K. Bhargava, and V. Bansal, "Gold nanoparticle-decorated keggin ions/ $/ \mathrm{TiO}_{2}$ photococatalyst for improved solar light photocatalysis," Langmuir, vol. 27, no. 11, pp. 6661-6667, 2011.

[25] A. Pearson, S. K. Bhargava, and V. Bansal, "UV-switchable polyoxometalate sandwiched between $\mathrm{TiO}_{2}$ and metal nanoparticles for enhanced visible and solar light photococatalysis," Langmuir, vol. 27, no. 15, pp. 9245-9252, 2011.

[26] K. Mori, K. Furubayashi, S. Okada, and H. Yamashita, "Synthesis of Pd nanoparticles on heteropolyacid-supported silica by a photo-assisted deposition method: an active catalyst for the direct synthesis of hydrogen peroxide," RSC Advances, vol. 2, no. 3, pp. 1047-1054, 2012.

[27] B. Keita, T. Liu, and L. Nadjo, "Synthesis of remarkably stabilized metal nanostructures using polyoxometalates," Journal of Materials Chemistry, vol. 19, no. 1, pp. 19-33, 2009.

[28] I. V. Kozhevnikov, "Catalysis by heteropoly acids and multicomponent polyoxometalates in liquid-phase reactions," Chemical Reviews, vol. 98, no. 1, pp. 171-198, 1998.

[29] N. Mizuno and M. Misono, "Heterogeneous catalysis," Chemical Reviews, vol. 98, no. 1, pp. 199-218, 1998.

[30] J. Liu, S. Liu, L. Qu, M. T. Pope, and C. Rong, "Derivatives of the 21-tungsto-9-antimonate heteropolyanion-part 1: inclusion of lanthanide cations," Transition Metal Chemistry, vol. 17, no. 4, pp. 311-313, 1992.

[31] J.-F. Liu, Y.-G. Chen, L. Meng, J. Guo, Y. Liu, and M. T. Pope, "Synthesis and characterization of novel heteropolytungstoarsenates containing lanthanides $\left[\mathrm{LnAs}_{4} \mathrm{~W}_{40} \mathrm{O}_{140}\right]^{25-}$ and their biological activity," Polyhedron, vol. 17, no. 9, pp. 15411546, 1998.

[32] M. H. Alizadeh, S. P. Harmalker, Y. Jeannin, J. Martin-Frere, and M. T. Pope, "A heteropolyanion with fivefold molecular symmetry that contains a nonlabile encapsulated sodium ion. The structure and chemistry of $\left[\mathrm{NaP}_{5} \mathrm{~W}_{30} \mathrm{O}_{110}\right]^{14-}$," Journal of the American Chemical Society, vol. 107, no. 9, pp. 2662-2669, 1985.

[33] F. F. Bamoharram, M. M. Heravi, M. Roshani, and N. Tavakoli, "N-oxidation of pyridine carboxylic acids using hydrogen peroxide catalyzed by a green heteropolyacid catalyst: preyssler's anion, $\left[\mathrm{NaP}_{5} \mathrm{~W}_{30} \mathrm{O}_{110}\right]^{14-}$," Journal of Molecular Catalysis A, vol. 252, no. 1-2, pp. 219-225, 2006.

[34] F. F. Bamoharram, M. M. Heravi, M. Roshani, M. Jahangir, and A. Gharib, "Preyssler catalyst, $\left[\mathrm{NaP}_{5} \mathrm{~W}_{30} \mathrm{O}_{110}\right]^{14-}$ : a green, efficient and reusable catalyst for esterification of salicylic acid with aliphatic and benzylic alcohols," Applied Catalysis A, vol. 302, no. 1, pp. 42-47, 2006.

[35] F. F. Bamoharram, "Role of polyoxometalates as green compounds in recent developments of nanoscience," Synthesis and Reactivity in Inorganic, Metal-Organic and Nano-Metal Chemistry, vol. 41, no. 8, pp. 893-922, 2011.

[36] A. Ayati, A. Ahmadpour, F. F. Bamoharram, M. M. Heravi, and H. Rashidi, "Photocatalytic synthesis of gold nanoparticles using preyssler acid and their photocatalytic activity," Chinese Journal of Catalysis, vol. 32, no. 6, pp. 978-982, 2011.

[37] G. Sun, Q. Li, R. Xu, J. Gu, M. Ju, and E. Wang, "Controllable fabrication of platinum nanospheres with a polyoxometalateassisted process," Journal of Solid State Chemistry, vol. 183, no. 11, pp. 2609-2615, 2010. 
[38] X. K. Fu, J. R. Chen, L. Q. Li, Q. Wang, and Y. Sui, "Organophosphonotungstic HPA of Keggin type with sulfo, taurine and glycine substituted ethylphosphonic acids as the coordinate center," Chinese Chemical Letters, vol. 14, no. 5, pp. 515-518, 2003.

[39] F. F. Bamoharram, "Vibrational spectra study of the interactions between keggin heteropolyanions and amino acids," Molecules, vol. 14, no. 9, pp. 3214-3221, 2009. 

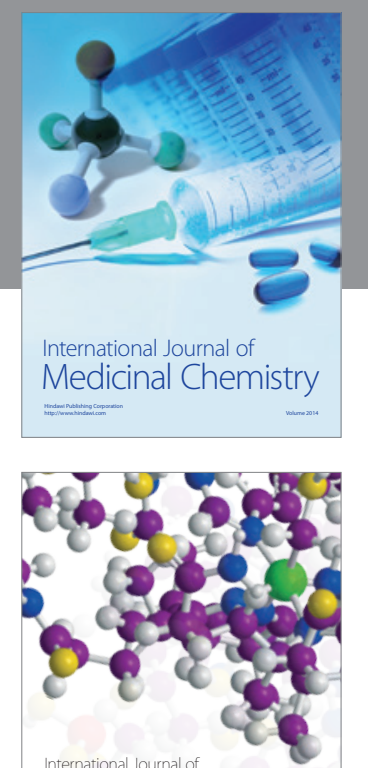

\section{Carbohydrate} Chemistry

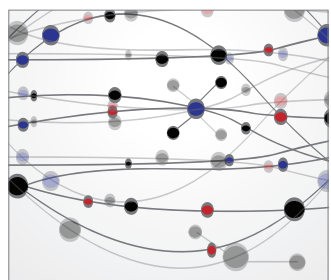

The Scientific World Journal
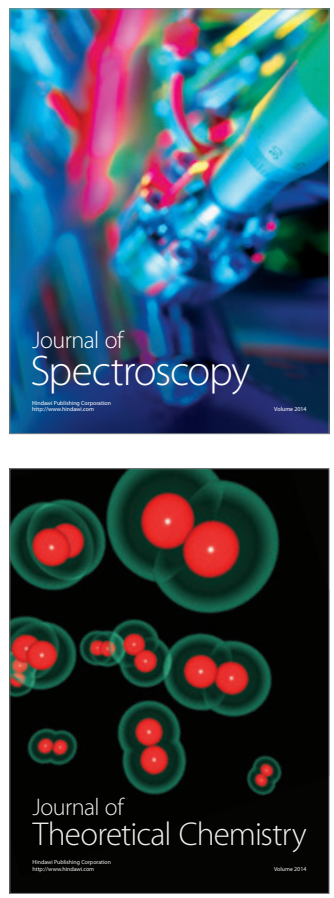
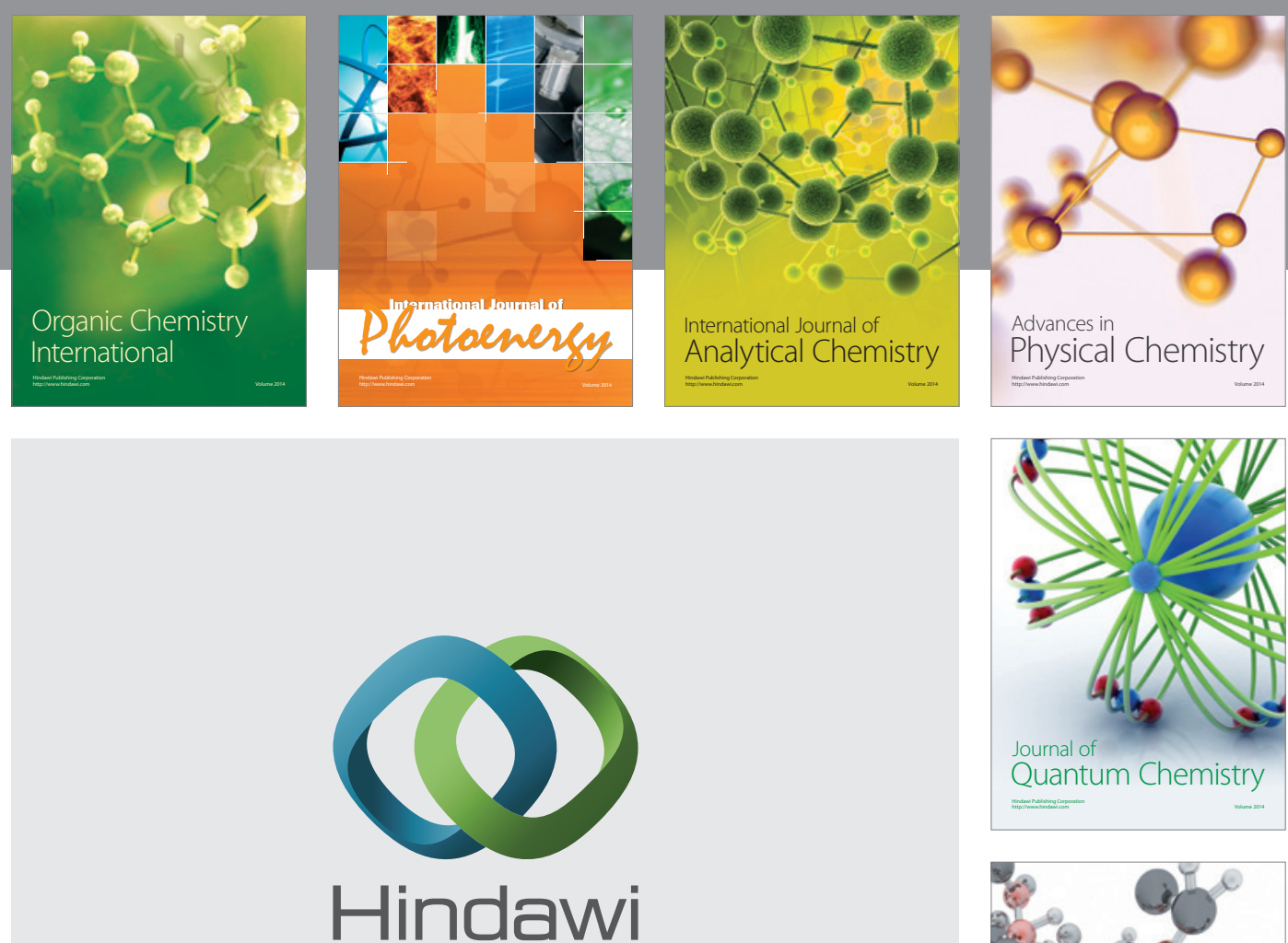

Submit your manuscripts at

http://www.hindawi.com

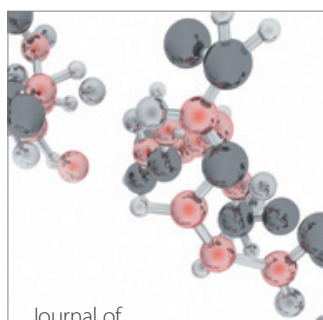

Analytical Methods

in Chemistry

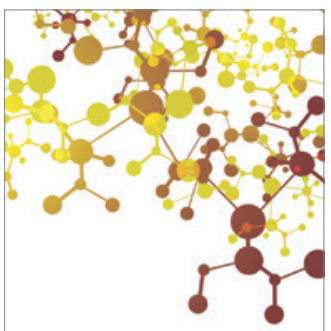

Journal of

Applied Chemistry

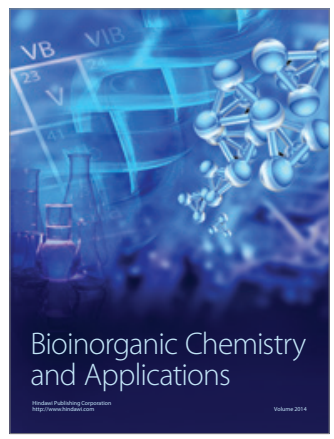

Inorganic Chemistry
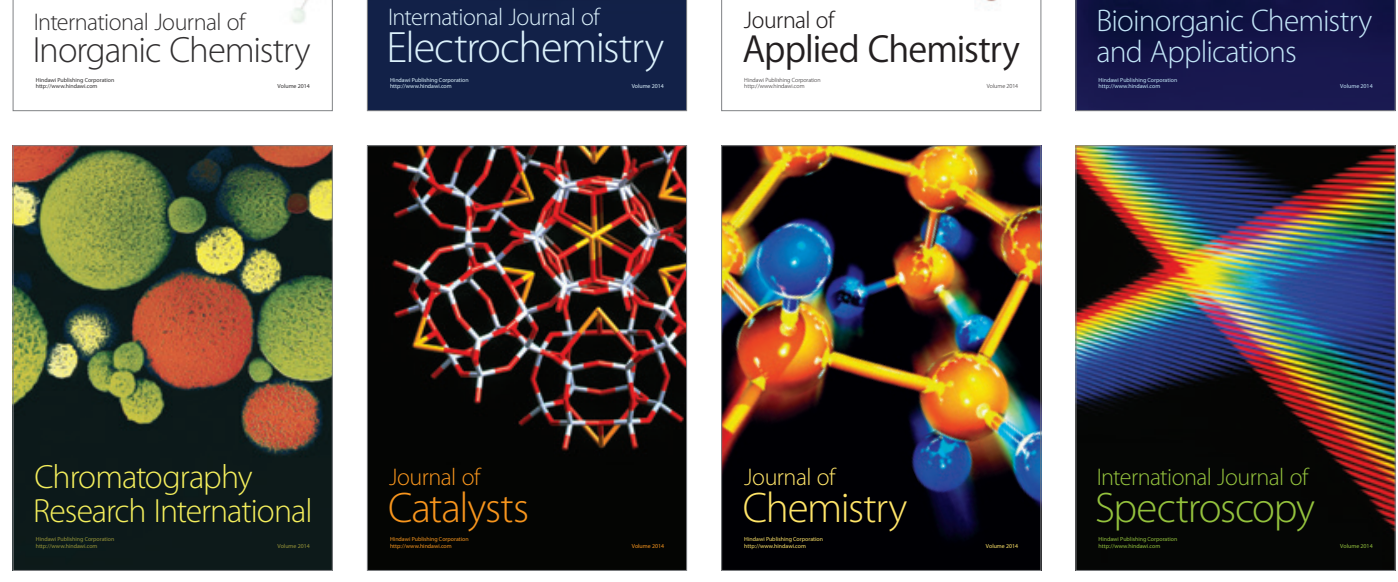